\title{
Preparation of Nitrogen-Doped Carbon Material from Monosodium Glutamate and Its Catalytic Performance
}

\author{
Ying Mei Zhou, Xiao Hui Wang, Ke Ying Cai*, Ji Ming Wu, Peng Wang, Ming Song \\ School of Chemistry and Chemical Engineering, Xuzhou University of Technology, Xuzhou, Jiangsu \\ 221018, China
}

Received: $19^{\text {th }}$ March 2018; Revised: $16^{\text {th }}$ August 2018; Accepted: 20th August 2018; Available online: 25th January 2019; Published regularly: April 2019

\begin{abstract}
Nitrogen doped (N-doped) carbon materials (NCMs) are generally used as electrode materials, and seldom used as catalysts in chemical reaction. In this work, NCMs were prepared by high-temperature pyrolysis using monosodium glutamate as sources of both carbon and nitrogen, magnesium acetate as a porogen, and nickel hydroxide as a graphitization catalyst. The catalytic performance of $\mathrm{NCMs}$ was investigated in the reduction of 4-nitrophenol (4-NP) with potassium borohydride at $30{ }^{\circ} \mathrm{C}$. As metalfree catalysts, all of the NCMs can catalyze the reaction. The graphitization degree and $\mathrm{N}$-doped amount of NCM have a great influence on the catalytic activity. The NCM annealed at $800{ }^{\circ} \mathrm{C}$ has higher activity and stability. The reaction rate constant can reach $0.57 \mathrm{~min}^{-1}$, and the activation energy was about $36.4 \mathrm{~kJ} / \mathrm{mol}$. Copyright (C) 2019 BCREC Group. All rights reserved
\end{abstract}

Keywords: Monosodium glutamate; Nitrogen-doped carbon material; Reduction; 4-Nitrophenol; Metalfree catalyst

How to Cite: Zhou, Y.M., Wang, X.H., Cai, K.Y., Wu, J.M., Wang, P., Song, M. (2019). Preparation of Nitrogen-Doped Carbon Material from Monosodium Glutamate and Its Catalytic Performance. Bulletin of Chemical Reaction Engineering \& Catalysis, 14 (1): 28-34 (doi:10.9767/bcrec.14.1.2377.28-34)

Permalink/DOI: https://doi.org/10.9767/bcrec.14.1.2377.28-34

\section{Introduction}

Carbon materials (CMs) have been widely used in adsorption, catalysis and electrochemistry due to their surface chemical inertness, mechanical stability and large specific surface area. However, the hydrophilicity of $\mathrm{CMs}$ is poor, which limits their application. Nitrogen doping in CMs can change the surface structure, enhance the hydrophilicity, and improve the electron transfer rate, so as to expand the application range [1]. At present, $\mathrm{N}$-doped $\mathrm{CMs}$ (NCMs) are mostly used as electrode materials [2]. However, as heterogeneous catalysts, NCMs

* Corresponding Author.

E-mail: caikeying@163.com (K. Y. Cai)

Telp: +86-13852081673, Fax: +86-516-85608300 have attracted increasing interests [1,3]. $\mathrm{N}$ atoms in NCMs have excellent coordinate ability with metal particles, which means that NCM is an ideal carrier for metal catalyst. Researches on NCMs as catalyst carriers for metal or metal oxide have been increasing. For example, noble metal particles immobilized on $\mathrm{N}$-doped carbon nanocages were used as catalysts for methanol electrooxidation [4], non-noble metals or metal oxides supported on NCMs were used as oxygen reduction catalysts for fuel cells [5,6], and cobalt supported on $\mathrm{N}$-doped ordered mesoporous carbon catalysts were used for Fischer-Tropsch synthesis [7].

However, the metal particles loaded on NCMs are easily aggregated or lost, resulting in the decrease of catalytic activity or even deactivation. As metal-free catalysts, NCMs have at- 
tracted increasing attention in recent years due to its advantages of good stability, environment friendliness and low cost. Podyacheva and Ismagilov [1] proposed that the defects in $\mathrm{CM}$ and the curling of basal plane induce local charges and increase the activity of CM. Based on this, $\mathrm{N}$ doping causes defects, leads to redistribution of charges, so as to improve the catalytic activity. In addition, $\mathrm{N}$ doping can produce acid and alkali sites in favor of their adsorbed reactants. NCM can be used with long term stability due to its acid, alkali, and hightemperature resistance [8]. These features enable NCMs to become high-performance catalysts. Researches on NCM as metal-free catalyst are increasing. For example, $\mathrm{N}$-doped graphenes were used in the selective oxidation of ethylbenzene [9], while $\mathrm{N}$-doped carbon nanotubes were used in the partial oxidation of $\mathrm{H}_{2} \mathrm{~S}[10,11]$ and the catalytic hydrochlorination of acetylene [12]. In addition, $\mathrm{N}$-doped graphene [3] and S-N-codoped CM [13] exhibited excellent performance in the reduction of $p$-nitrophenol (4-NP).

The 4-NP is a precursor of 4-aminophenol (4-AP) which can be used for the production of medicine, pesticides, insecticides, and fungicides etc. On the other hand, the 4-NP has serious risks to ecosystem and human health, due to its high toxicity, stability in the environment, water solubility, and poor biodegradation. Compared with the 4-NP, the 4-AP is of low toxicity, instability, and biodegradation. Therefore, the catalytic reduction of 4-NP to 4-AP with $\mathrm{NaBH}_{4}$ has been widely studied. Most of the existing researches on the reaction are based on metallic catalysts, such as: $\mathrm{Ag}$ [14], $\mathrm{Au}$ [15], $\mathrm{Cu}$ [16], Co [17], and $\mathrm{Bi}$ [18], which are restricted due to limited reserves, high cost and low stability.

Although the disadvantages of the metallic catalyst could be avoided by using $\mathrm{N}$-doped graphene [3] and S-N-codoped CM [13], the preparation processes of these NCMs are complicated. In this work, NCMs were prepared by a simple method using monosodium glutamate (MSG) as sources of $\mathrm{C}$ and $\mathrm{N}$. The catalytic activity of the as-prepared catalysts in the reduction of 4-NP was evaluated. The influence of the preparation conditions on the catalytic performance was also investigated.

\section{Materials and Methods}

\subsection{Materials}

MSG, magnesium acetate tetrahydrate, and 4-NP were purchased from Tianjin Fuchen Reagent Co. Ltd. (China). Potassium borohydride
(95\%) and nickel hydroxide were purchased from Sinopharm Chemical Reagent Co. Ltd. (China). All reagents were of analytical pure grade and used without further purification. Ultrapure water was used throughout the whole experiment.

\subsection{Preparation of NCMs}

The NCMs were prepared via a pyrolysis method using $\mathrm{Ni}(\mathrm{OH})_{2}$ as the graphitization catalyst and MSG as $\mathrm{C}$ and N sources. Briefly, $5.0 \mathrm{~g}$ of MSG, $1.6 \mathrm{~g}$ of $\mathrm{Mg}\left(\mathrm{CH}_{3} \mathrm{COO}\right)_{2} \cdot 4 \mathrm{H}_{2} \mathrm{O}$, and $0.05 \mathrm{~g}$ of $\mathrm{Ni}(\mathrm{OH})_{2}$ were ground evenly in a mortar, and then the mixture was taken in a quartz boat and placed inside a tubular furnace. The mixture was heated in $\mathrm{N}_{2}$ at a rate of $10{ }^{\circ} \mathrm{C} / \mathrm{min}$ to 700,800 , and $900{ }^{\circ} \mathrm{C}$ for $2 \mathrm{~h}$, respectively. After cooling to room temperature, the resulting composites were treated with a solution of hydrochloric acid (6 M) at 80 ${ }^{\circ} \mathrm{C}$ for $10 \mathrm{~h}$ to remove nickel, followed by washing with deionized water and ethanol, and drying at $80{ }^{\circ} \mathrm{C}$ for $12 \mathrm{~h}$. The resulting samples were denoted NCM-700Ni, NCM-800Ni, and NCM-900Ni, respectively. For comparison, we also prepared NCMs from MSG without $\mathrm{Ni}$ catalyst, denoted NCM-800.

\subsection{Catalyst Characterization}

The X-ray diffraction (XRD) patterns were recorded on a Ultima IV diffractometer (Rigaku) equipped with a $\mathrm{Cu} \mathrm{K}_{a}$ radiation at $2^{\circ}$ steps. The measurements of X-ray photoelectron spectroscopy (XPS) were carried out in an Escalab 250Xi spectrometer (Thermo) using $\mathrm{Al}-\mathrm{K}_{a} \mathrm{X}$-ray as the excitation source $(225 \mathrm{~W})$. Raman spectra were measured on a DXR2 Raman spectrometer (Thermo) using a laser with an excitation wavelength of $532 \mathrm{~nm}$ at room temperature.

\subsection{Catalytic Reduction of 4-NP}

The catalytic performance of the asprepared NCMs was investigated by using the reduction of 4-NP with excessive $\mathrm{KBH}_{4}$ as a model reaction. Briefly, $100 \mathrm{~mL}$ of $4-\mathrm{NP}$ solution $(2 \mathrm{mmol} / \mathrm{L})$ was mixed with $0.03 \mathrm{~g}$ of catalyst in a beaker at $30{ }^{\circ} \mathrm{C}$. Then $0.3 \mathrm{~g}$ of $\mathrm{KBH}_{4}$ was rapidly added under constant stirring. Samples were directly withdrawn from the reaction mixture at certain time intervals. Since the UV absorbance of $4-\mathrm{NP}$ at $400 \mathrm{~nm}$ is proportional to its concentration in the solution, the absorbance ratio $A_{t} / A_{0}$ is equal to the concentration ratio $C_{t} / C_{0}$ of 4 -NP [19]. Therefore, the reaction progress can be directly monitored 
by a UV-5500PC UV-Vis spectrometry (Shanghai Metash). To investigate the stability of the as-prepared catalysts, the used catalysts were separated from the reaction mixture by centrifugation, washed with deionized water several times and reused. The conversion of 4-NP was defined as Equation (1).

Conversion $=\frac{\left(1-C_{t}\right)}{C_{0}} \times 100 \%=\frac{\left(1-A_{t}\right)}{A_{0}} \times 100 \%$

\section{Results and Discussion}

\subsection{Characterization of Catalysts}

X-ray powder diffraction analysis was used to identify the crystal structure of the NCMs, and the results are shown in Figure 1 . The broad diffraction peaks at about $25^{\circ}$ for all samples can be indexed as (002) diffraction plane of the hexagonal phase graphite (JCPDS No. 411487) [20]. The broad pattern of diffraction peaks indicates the poor graphitization degree for NCM-700Ni and NCM-800. However, the peaks of NCM-800Ni and NCM-900Ni at $26.5^{\circ}$ are sharper, indicating high graphitization degree of the two samples. According to Equation (2), the graphitization degrees had been calculated to be $89.1 \%$ and $71.5 \%$, respectively [21]. The result indicates that the graphitization degree of the samples increased with the increasing pyrolysis temperature, and nickel can also promote graphitization. In addition, there is no diffraction peak of nickel or its compounds, indicating that nickel may be almost completely removed from the samples.

$$
\text { Graphitization degree }=\frac{\left(0.344-d_{002}\right)}{0.0086}
$$

Raman spectrometer was used to characterize the as-prepared samples. As shown in

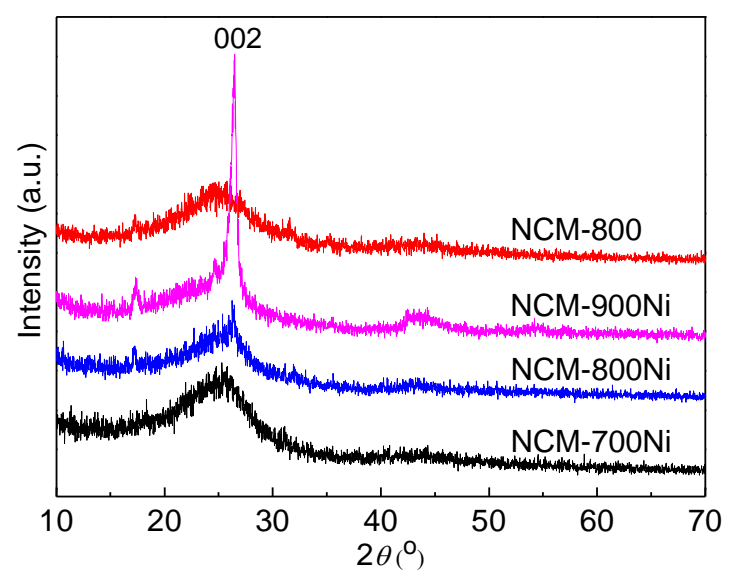

Figure 1. XRD patterns of the NCMs
Figure 2, all the samples showed an obvious D band at about $1350 \mathrm{~cm}^{-1}$ and a $\mathrm{G}$ band at about $1580 \mathrm{~cm}^{-1}$. The $\mathrm{G}$ band corresponds to the zone center $\mathrm{E}_{2 \mathrm{~g}}$ mode regarding phonon vibrations in the $\mathrm{sp}^{2}$ carbon materials, while the $\mathrm{D}$ band corresponds to the $\mathrm{sp}^{2} \mathrm{C}$ with defects [21]. Therefore, the intensity ratio of the $G$ and $D$ bands $\left(I_{\mathrm{G}} / I_{\mathrm{D}}\right)$ can be used to characterize the graphitization degree of CMs. Compared with NCM-800, NCM-800Ni has a higher $I_{\mathrm{G}} / I_{\mathrm{D}}$ ratio, indicating that nickel can improve graphitization remarkably. For the nickel-catalyzed samples, the $I_{\mathrm{G}} / I_{\mathrm{D}}$ ratio increased with the pyrolysis temperature. The $I_{\mathrm{G}} / I_{\mathrm{D}}$ ratios of NCM- $800 \mathrm{Ni}$ and NCM-900Ni are 1.29 and 2.39, respectively, indicating higher graphitization degree of the two samples. The results are in agreement with the results from XRD patterns.

XPS measurements were performed to analyze the elemental composition and N-bonding configurations of the samples. As shown in Figure 3A, the XPS spectra reveal the presence of $\mathrm{C}, \mathrm{N}$, and $\mathrm{O}$ elements in all samples. Except for the NCM-800 sample, the other three samples also contain less than 0.2 at\% of residual nickel. This result is consistent with the finding from XRD patterns. The residual nickel in the samples may be attributed to nickel encapsulated by carbon particles and thus, is not accessible to the acid during the acid treatment. Such residual nickel is not readily accessible to the reactants during the reaction process.

According to Figure 3A, the $\mathrm{N}$ contents were calculated and listed in Table 1. As shown in Table 1, the $\mathrm{N}$ content decreases with the increase of pyrolysis temperature. The pyrolysis temperatures of NCM800-Ni and NCM-800 are the same, but the $\mathrm{N}$ content of $\mathrm{NCM} 800-\mathrm{Ni}$ is higher than that of NCM-800. The result indicates that nickel can facilitate the $\mathrm{N}$-doping in

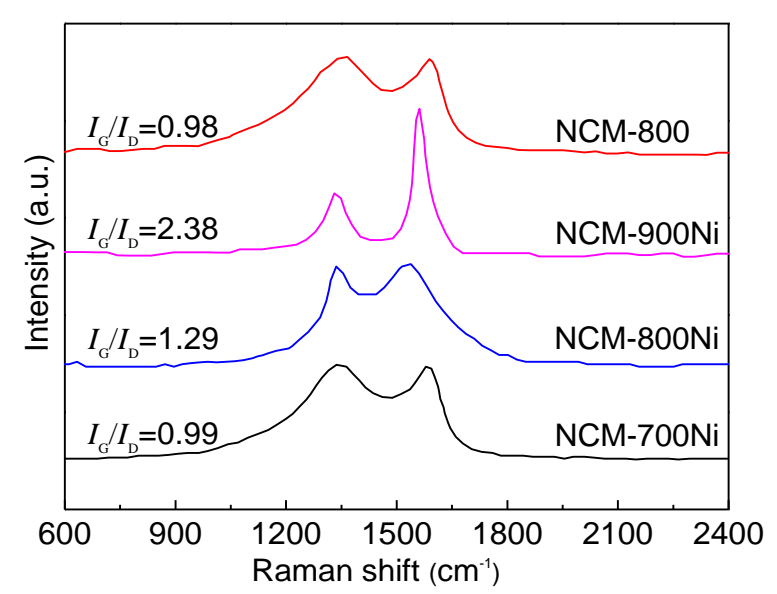

Figure 2. Raman spectra of the NCMs 

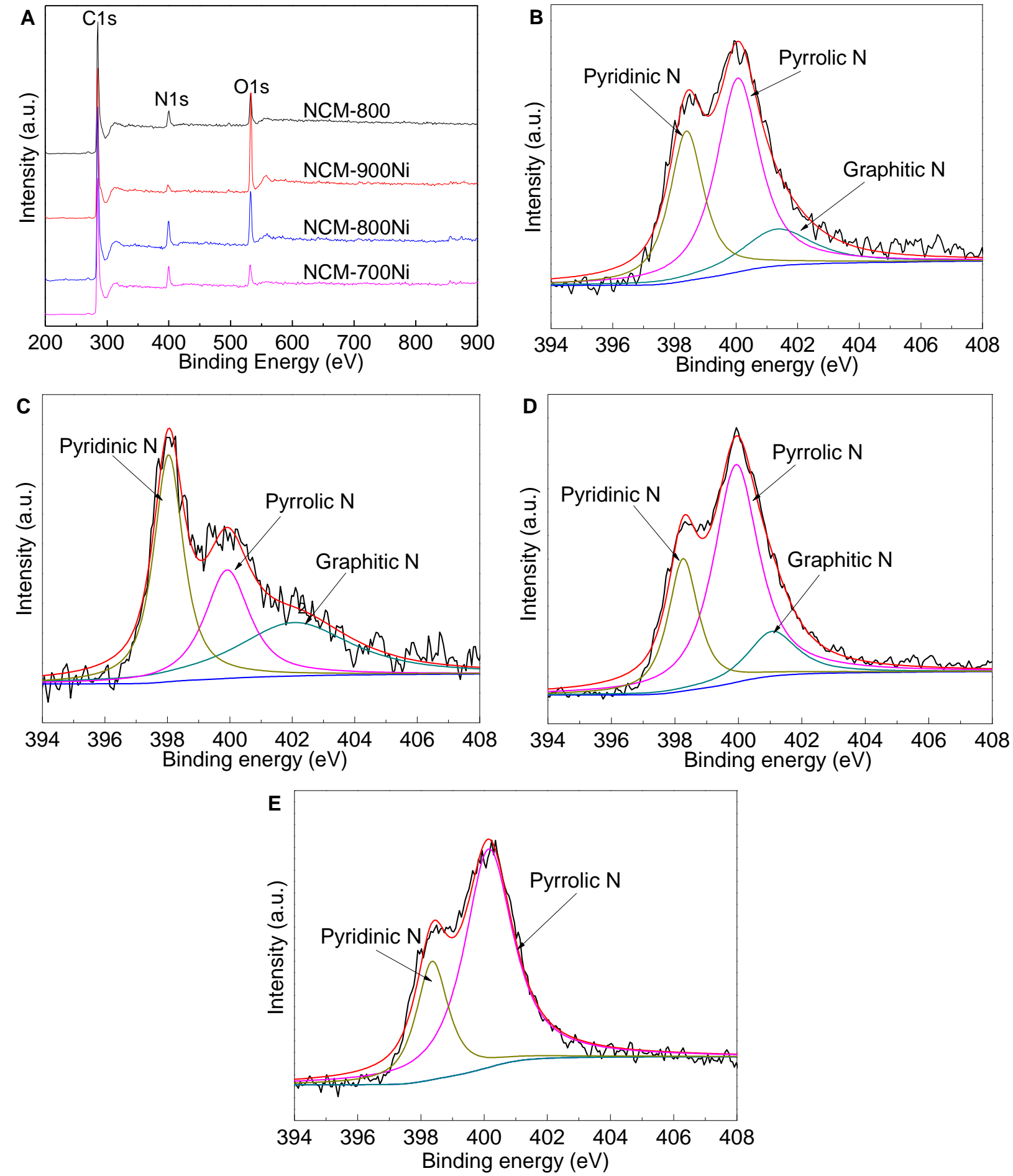

Figure 3. (A) XPS survey scan. High-resolution N1s spectra of (B) NCM-800, (C) NCM-900Ni, (D) NCM- $800 \mathrm{Ni}$, and (E) NCM-700Ni

Table 1. Nitrogen species and contents in the samples

\begin{tabular}{ccccc}
\hline \multirow{2}{*}{ Sample } & \multirow{2}{*}{ Total N (\%) } & \multicolumn{3}{c}{ N species (\%) } \\
\cline { 3 - 5 } & & Pyridinic & Pyrrolic & Graphitic \\
\hline NCM-700Ni & 9.37 & $2.9(26.6)$ & $6.88(73.4)$ & $0(0)$ \\
NCM-800Ni & 9.32 & $234(25.1)$ & $5.78(62.0)$ & $1.20(12.9)$ \\
NCM-900Ni & 4.33 & $1.62(37.5)$ & $1.28(29.6)$ & $1.42(32.9)$ \\
NCM-800 & 8.25 & $2.62(31.8)$ & $4.27(51.8)$ & $1.35(16.4)$ \\
\hline
\end{tabular}


the material. As shown in Figure 3B-E, the XPS spectra of N1s were deconvoluted to three $\mathrm{N}$ species: pyridinic $\mathrm{N}(398.5 \mathrm{eV})$, pyrrolic $\mathrm{N}$ $(400.0 \mathrm{eV})$, and graphitic N (401.5 eV). Based on the area of XPS peaks, the contents of different $\mathrm{N}$ species were calculated and shown in Table 1. The relative percentages of graphitic N in NCM-700Ni, NCM-800Ni, NCM-900Ni and NCM-800 are $0 \%, 12.9 \%, 32.9 \%$, and $16.4 \%$, respectively. The results show that the graphitic $\mathrm{N}$ percentage increases with the increase of pyrolysis temperature.

\subsection{Catalytic Activity}

To investigate the catalytic activity of the NCMs, the reduction of 4-NP with excess $\mathrm{KBH}_{4}$ was chosen as a model reaction. Owing to the large excess of the $\mathrm{KBH}_{4}$ concentration, it can be considered as a constant during the reaction. Therefore, the reaction can be regarded as pseudo-first-order reaction. Since the absorbance of 4-NP is proportional to its concentration in the mixture, the ratio of $A_{\mathrm{t}} / A_{0}$ is equal to the concentration ratio $C_{t} / C_{0}$ of 4 -NP [18]. Hence, the kinetic equation for the reduction can be written as Equation (3).

$$
\ln \left(\frac{A_{t}}{A_{0}}\right)=\ln \left(\frac{C_{t}}{C_{0}}\right)=-k t
$$

According to the plot of $\ln \left(A_{t} / A_{0}\right)$ versus reaction time, the apparent rate constants for the reaction can be obtained from the slope of the curve fitting line (Figure 4) [14]. The rate constants calculated according to the line slopes are 0.07 (NCM-800), 0.12 (NCM-700Ni), 0.57 (NCM-800Ni), and $0.24 \mathrm{~min}^{-1}(\mathrm{NCM}-900 \mathrm{Ni})$, respectively. The CM-800 without nitrogen doped has little activity, but the other NCMs have

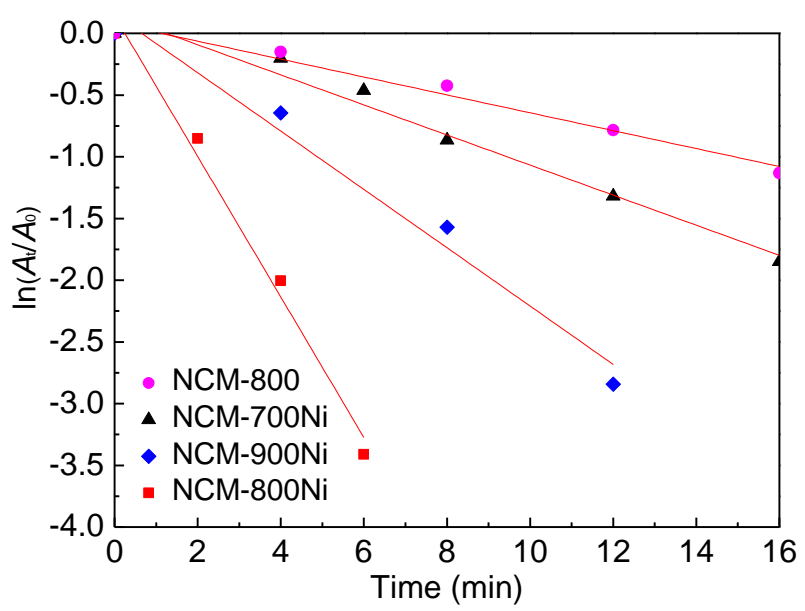

Figure 4. The relationship of $\ln \left(A_{t} / A_{0}\right)$ versus reaction time higher activity. The result shows that the Ndoping can improve the activity of the catalyst. For NCMs, the NCM-800 has the lowest activity, and the possible explanation is that the graphitization degrees of the NCM-700Ni, NCM- $800 \mathrm{Ni}$, and NCM-900Ni catalysts are higher than that of the NCM-800 catalyst. High graphitization is beneficial to electron transfer which can improve the reaction rate [1].

Additionally, we further investigated the relationship between activity and $\mathrm{N}$ amount in the NCM-700Ni, NCM- $800 \mathrm{Ni}$, and NCM-900Ni samples. As shown in Figure 5, the relationship between the rate constant and the amount of pyrrolic $\mathrm{N}$, pyridinic $\mathrm{N}$, or graphtic $\mathrm{N}$ is not clear. However, the rate constant increases with the total amount of pyridinic $\mathrm{N}$ and graphtic N. The observations suggest that pyridinic $\mathrm{N}$ and graphtic $\mathrm{N}$ species are involved in the active sites for the reaction. The $\mathrm{N}$ doping can induce charge redistribution in NCMs, because the electronegativity of $\mathrm{N}$ atom is larger than that of $\mathrm{C}$ atom. The positive charges of $\mathrm{C}$ atoms adjacent to pyrrolic $\mathrm{N}$, pyridinic $\mathrm{N}$ and graphitic $\mathrm{N}$ are $0.17,0.22$, and 0.22 e, respectively [23], while 4-NP ion is charged negatively. Therefore, the $\mathrm{N}$ doping can enhance the adsorption of 4-NP ions on the NCMs. The C atoms adjacent to pyridinic $\mathrm{N}$ and graphitic $\mathrm{N}$ have more positive charges, leading to stronger adsorption of 4-NP ions, so as to improve the catalytic activity. This means that pyridinic and graphitic $\mathrm{N}$ are the active sites in the NCMs.

Using NCM- $800 \mathrm{Ni}$ as the catalyst, the effect of temperature on the reaction was investigated. The rate constant of the reaction in-

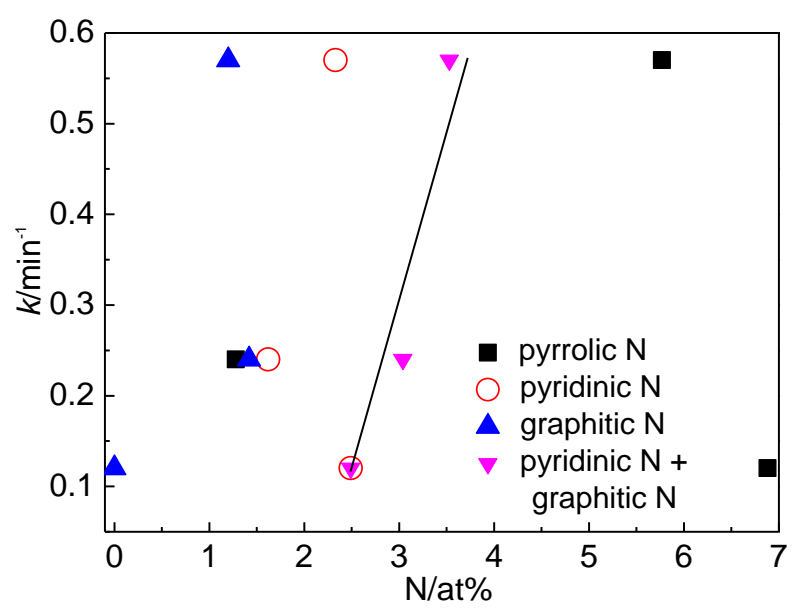

Figure 5. Relationship between the catalyst activity and the amount of $\mathrm{N}$ 


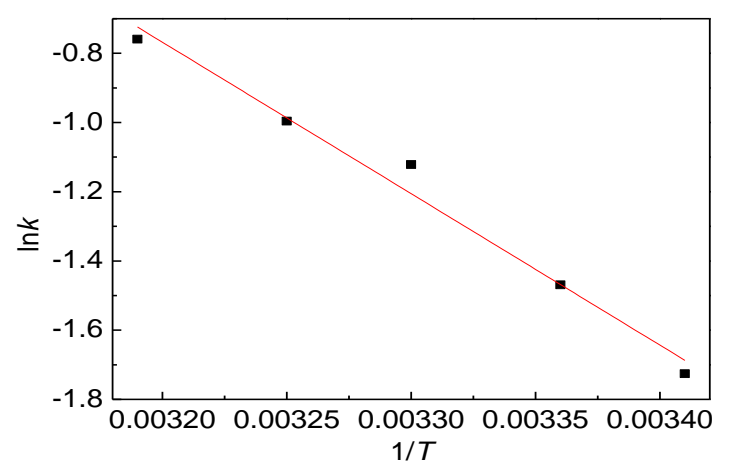

Figure 6. Plot of $\ln k$ versus $1 / T$ for estimation of the activation energy

creased with increasing temperature for the catalytic reaction process. The relationship between $k$ and $T$ can be expressed as Equation (4).

$$
\ln k=\ln A-\frac{E_{\mathrm{a}}}{R T}
$$

where, $E_{\mathrm{a}}$ is activation energy, $A$ is Arrhenius factor, $R$ is ideal gas constant, and $T$ is temperature. The value of $E_{\text {a }}$ was calculated to be about $36.4 \mathrm{~kJ} / \mathrm{mol}$ from the plot of $\ln k$ versus $1 / T$ (Figure 6$)$. The $E_{\text {a }}$ is lower than that of the same reaction catalyzed by metal catalyst such as $\mathrm{Ag} / \mathrm{TiO}_{2}$ (36.69 kJ/mol) [14], gold nanoparticles supported on oxidized mesoporous carbon (86.8 kJ/mol) [15], and $\mathrm{Cu}$ dendrimerencapsulated nanoparticles $(65.5 \mathrm{~kJ} / \mathrm{mol})$ [16]. The result indicates that the catalytic reaction has a low potential barrier, that is, the catalyst has high activity for the reaction.

Figure 7 shows the reusability of the NCM$800 \mathrm{Ni}$ catalyst for the reduction of $4-\mathrm{NP}$ with $\mathrm{KBH}_{4}$ at $30{ }^{\circ} \mathrm{C}$. After reused for 9 cycles, the conversion of 4-NP according to Equation (1) had no significant decrease. This result shows that the NCM-800Ni catalyst was not deactivated significantly during the reaction, washing, and separation processes. Compared with a metal-based catalyst, no metal particle was loaded on the surface of NCM, hence there is no aggregation or loss of metal particles during the reaction. This is the cause that the NCM catalyst can keep excellent stability in the reaction. The activity decreased slightly after each cycle, probably due to the gradual loss of particles with repeated centrifugal separation.

\section{Conclusions}

Using cheap MSG as a raw material, nickel hydroxide as a graphitization catalyst and magnesium acetate as a porogen, the NCMs were prepared by high-temperature pyrolysis. Improving pyrolysis temperature and adding

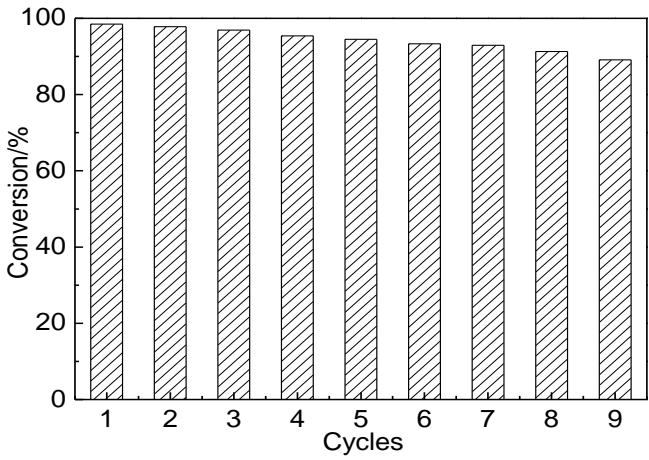

Figure 7. The reusability of NCM-800Ni as a catalyst for the reduction of $4-\mathrm{NP}$

nickel can promote graphitization of the NCMs remarkably. The $\mathrm{N}$ content in the NCM decreases with increasing pyrolysis temperature, while the relative percentage of graphite $\mathrm{N}$ increases in the NCM. The catalytic performance was demonstrated by the study on the reduction 4-NP to 4-Ap with $\mathrm{KBH}_{4}$ at $30{ }^{\circ} \mathrm{C}$. The $\mathrm{NCM}$ carbonized at $800{ }^{\circ} \mathrm{C}$ with suitable graphitization degree and $\mathrm{N}$ content has excellent catalytic activity. The reaction rate constant can reach $0.57 \mathrm{~min}^{-1}$ for the reaction catalyzed by NCM- $800 \mathrm{Ni}$, and the activation energy of the reaction was about $36.4 \mathrm{~kJ} / \mathrm{mol}$. In addition, the NCM particles exhibited quite good stability. Their activity had no significant decrease after reused for 9 cycles.

\section{Acknowledgments}

The authors wish to acknowledge the financial supports from the Science and Technology Department of Jiangsu Province (BE2015041 and BK20171169), and Jiangnan University (3516010241140190/002).

\section{References}

[1] Podyacheva, O.Y., Ismagilov, Z.R. (2015). Nitrogen-Doped Carbon Nanomaterials: To the Mechanism of Growth Electrical Conductivity and Application in Catalysis. Catalysis Today. 249(23): 12-22.

[2] Wang, H.B., Maiyalagan, T., Wang, X. (2012). Review on Recent Progress in NitrogenDoped Graphene: Synthesis, Characterization, and Its Potential Applications. ACS Catalysis. 2(5): 781-794.

[3] Kong, X.K., Sun, Z.Y., Chen, M., Chen, C.L., Chen, Q.W. (2013). Metal-Free Catalytic Reduction of 4-Nitrophenol to 4-Aminophenol by N-Doped Graphene. Energy \& Environmental Science. 6(11): 3260-3266. 
[4] Li, D.Q., Zhang, Z.Q., Zang, P.Y., Ma, Y.W., Wu, Q., Yang, L.J., Chen, Q., Wang, X.Z., Hu, Z. (2016). Alloyed Pt-Ru Nanoparticles Immobilized on Mesostructured Nitrogen-Doped Carbon Nanocages for Efficient Methanol Electrooxidation. ACTA Chimica Sinica. 74(7): 587-592.

[5] Wang, Y.M., Luo, E.G., Xiao, M.L., Ge, J.J., Liu, C.P., Xing, W. (2017). Recent Progress in Active Sites for Non-Noble Metal CarbonBased Oxygen Reduction Catalysts. Scientia Sinica Chimica. 47(5): 554-564.

[6] Duan, J.J., Chen, S., Dai, S., Qiao, S.Z. (2014). Shape Control of $\mathrm{Mn}_{3} \mathrm{O}_{4}$ Nanoparticles on Nitrogen-Doped Graphene for Enhanced Oxygen Reduction Activity. Advanced Functional Materials. 24(14): 2072-2078.

[7] Yang, Y.F., Jia, L.T., Hou, B., Li, D.B., Wang, J.G., Sun, Y.H. (2014). The Effect of Nitrogen on the Autoreduction of Cobalt Nanoparticles Supported on Nitrogen-Doped Ordered Mesoporous Carbon for the Fischer-Tropsch Synthesis. Chemcatchem. 6(1): 319-327.

[8] Sun, X.Y., Wang, R., Su, D.S. (2013). Research Progress in Metal-Free Carbon-Based Catalysts. (2013). Chinese Journal of Catalysis. 34(3): 508-523.

[9] Tang, P., Gao, Y.J., Yang, J.H., Li, W.J., Zhao, H.B., Ma, D. (2014). Growth Mechanism of NDoped Graphene Materials and Their Catalytic Behavior in the Selective Oxidation of Ethylbenzene. Chinese Journal of Catalysis. 35(6): 922-928.

[10] Ba, H., Duong-Viet, C., Liu, Y.F., Nhut, J.M., Granger, P., Ledoux, M.J., Pham-Huu, C. (2016). Nitrogen-Doped Carbon Nanotube Spheres as Metal-Free Catalysts for the Partial Oxidation of $\mathrm{H}_{2} \mathrm{~S}$. Comptes Rendus Chimie. 19(10): 1303-1309.

[11] Duong-Viet, C., Ba, H., Liu, Y.F., TruongPhuoc, L., Nhut, J.M., Pham-huu, C. (2014). Nitrogen-Doped Carbon Nanotubes on Silicon Carbide as a Metal-Free Catalyst. Chinese Journal of Catalysis. 35(6): 906-913.

[12] Zhou, K., Li, B., Zhang, Q., Huang, J.Q., Tian, G.L., Jia, J.C., Zhao, M.Q., Luo, G.H., Su, D.S., Wei, F. (2014). The Catalytic Pathways of Hydrohalogenation over Metal Free Nitrogen-Doped Carbon Nanotubes. ChemSusChem. 7(3): 723-728.

[13] Pan, J., Song S.Y., Li J.Q., Wang F., Ge X., Yao S., Wang X., Zhang H.J. (2017). Solid Ion Transition Route to 3D S-N-Codoped Hollow Carbon Nanosphere/Grapheme Aerogel as a Metal-Free Handheld Nanocatalyst for Organic Reactions. Nano Research. 10(10): 34863495 .

[14] Mohamed, M.M., Al-Sharif, M.S. (2012). One Pot Synthesis of Silver Nanoparticles Sup- ported on $\mathrm{TiO}_{2}$ Using Hybrid Polymers as Template and Its Efficient Catalysis for the Reduction of 4-Nitrophenol. Materials Chemistry and Physics. 136(2-3): 528-537.

[15] Guo, P.C., Tang, L., Zeng, G.M., Huang, B.B., Dong, H.R., Zhang, Y., Zhou, Y.Y., Deng, Y.C., Ma, L.L., Tan, S.R. (2016). Catalytic Reduction-Adsorption for Removal of $p$ Nnitrophenol and Its Conversion $p$ Aminophenol from Water by Gold Nanoparticles Supported on Oxidized Mesoporous Carbon. Journal of Colloid and Interface Science. 469(1): 78-85.

[16] Nemanashi, M., Meijboom, R. (2013). Synthesis and Characterization of $\mathrm{Cu}, \mathrm{Ag}$, and $\mathrm{Au}$ Dendrimer-Encapsulated Nanoparticles and Their Application in the Reduction of 4Nitrophenol to 4-Aminophenol. Journal of Colloid and Interface Science. 389(1): 260267.

[17] Ma, H., Wang, H., Wu, T., Na, C. (2016). Highly Active Layered Double HydroxideDerived Cobalt Nano-Catalysts for $p$ Nitrophenol Reduction. Applied Catalysis B: Environmental. 180: 471-479.

[18] Cai, K.Y., Zhou, Y.M., Wang, P., Li, H., Li, Y., Tao, W. (2018). Preparation of NitrogenDoped Carbon Materials from Monosodium Glutamate and Application in Reduction of $p$ Nitrophenol. Bulletin of Chemical Reaction Engineering \& Catalysis. 13(1): 89-96.

[19] Tang, M., Zhang, S., Li, X., Pang, X., Qiu, H. (2014). Fabrication of Magnetically Recyclable $\mathrm{Fe}_{3} \mathrm{O}_{4} @ \mathrm{Cu}$ Nanocomposites with High Catalytic Performance for the Reduction of Organic Dyes and 4-Nitrophenol. Materials Chemistry and Physics. 148(3): 639-647.

[20] Kang, W.J., Li, H.B., Ai, M., Wei, S.Y., Gao, H.Z., Liu, J.F., Qian, Y.T. (2014). Synthesis of Nitrogen-Doped Carbon and Application in Highly Selective and Sensitive Dopamine Sensing. Materials Letters. 116(2): 374-377.

[21] Li, C.J., Ma, B.X., Huo, X.X. (1999). Characterization of Graphitization Degree in $\mathrm{C} / \mathrm{C}$ Composites. New Carbon Materials. 14(1): 1925.

[22] Liu, J.Y., Yan, X.D., Wang, L.Z., Kong, L.M., Jian, P.M. (2017). Three-Dimensional Nitrogen-Doped Graphene Foam as Metal-Free Catalyst for the Hydrogenation Reduction of $p$-Nitrophenol. Journal of Colloid and Interface Science. 497: 102-107.

[23] Huang, G., Yang, L., Ma, X., Jiang, J., Yu, S.H., Jiang, H.L. (2016). Metal-Organic Framework Templated Porous Carbon for Highly Efficient Catalysis: The Critical Role of Pyrrolic N Species. Chemistry-A European Journal. 22: 3470-3477. 